\title{
MOF-derived three-dimensional ordered porous carbon nanomaterial for efficient alkaline zinc-air batteries
}

\author{
Qiuhong Sun ${ }^{1}$, Kai Zhu ${ }^{1}$, Xiangli Ji ${ }^{1}$, Dandan Chen ${ }^{1}$, Cheng Han ${ }^{1}$, Ting-Ting $\mathrm{Li}^{2}$, Yue Hu${ }^{1}$, \\ Shaoming Huang ${ }^{3}$ and Jinjie Qian ${ }^{1,2^{*}}$
}

\begin{abstract}
The design and preparation of non-noble metal catalysts with high catalytic activity and robust stability are important in the research of metal-air batteries and fuel cells. Here, a three-dimensional (3D) hierarchically ordered porous carbon nanomaterial was conveniently synthesized with zeolite-imidazole framework (ZIF-8) carbonization using the silica-template method and carbon nanotube (CNT) growth. The addition of an iron source endows the porous mFeNCCNT with Fe-based nanoparticles and abundant atomically dispersive $\mathrm{Fe}-\mathrm{N}_{x}$ sites from its nitrogen-incorporated graphitic carbon matrix. As a result, the $3 \mathrm{D}$ porous structure reduces the charge transport resistance, and the iron and nitrogen codoped carbon exhibits excellent catalytic activity for oxygen reduction reaction $(\mathrm{ORR})$ similar to that of commercial $\mathrm{Pt} / \mathrm{C}$. Meanwhile, the interwoven CNTs obtained under urea catalysis further shorten the ion and electron diffusion pathway. Experimental and theoretical analyses revealed that the optimized $\mathrm{mFeNC}$-CNT has a high ORR activity with a half-wave potential of $0.908 \mathrm{~V}$ and a large open-circuit voltage $(1.556 \mathrm{~V})$ when applied on zinc-air batteries. This work provides a promising strategy for the rational design and facile synthesis of high-performing non-noble metal-based electrocatalysts for energy storage, conversion, and transport applications.
\end{abstract}

Keywords: metal-organic framework, silica template, carbon nanotube, oxygen reduction reaction, $\mathrm{Zn}$-air battery

\section{INTRODUCTION}

With the increasing demand for green energy and environmental protection, extensive studies have focused on advanced energy-related technologies that can meet present and future energy needs [1-3]. Among these, sustainable fuel cells and metal-air batteries are considered the next generation of clean energy because of their high conversion efficiency and environmental friendliness [4-6]. For example, these devices can directly convert the chemical energy of hydrogen and oxygen into electrical energy through a pair of redox reactions and produce only water in $\mathrm{H}_{2}-\mathrm{O}_{2}$ fuel cells. However, the complex and slow kinetics of the cathode and the electrochemical oxygen reduction reaction (ORR) with high reaction overpotential severely hinder their large-scale applications $[7,8]$. Commercial carbon-supported platinum nanomaterials have been recognized as excellent ORR catalysts due to their outstanding electrocatalytic performance [4,9]. Nevertheless, the shortcomings of noble metals such as limited reserve, high cost, and poor stability greatly impede their prospective applications $[10,11]$. Therefore, the design and fabrication of non-noble metal-based catalysts with low price, high efficiency, and robust durability are of great importance.

Many theoretical and experimental methods have verified that codoping metal $\mathrm{Fe}$ and non-metal $\mathrm{N}$ into a carbon substrate could produce high ORR catalytic activity $[12,13]$. On the one hand, heteroatom $\mathrm{N}$ with a small atomic radius and high electronegativity can structurally alter the charge density and carbon atom distribution, generate electronegative sites, promote oxygen adsorption, reduce the energy barrier, and further improve the binding capacity of the catalyst to interact with reaction intermediates $[14,15]$. On the other hand, nitrogen-containing carbon materials loaded with $\mathrm{Fe}$ atoms and calcined by hightemperature pyrolysis usually generate thermodynamically stable and catalytically active $\mathrm{Fe}-\mathrm{N}_{x}$ species that provide strong oxygen adsorption capacity and further reduce the energy barrier to destroy $\mathrm{O}=\mathrm{O}$ bonds $[16,17]$. However, the abundant $\mathrm{Fe}$ particles will inevitably aggregate during thermal treatment to form Fe nanoparticles (NPs), which in turn weakens the electrocatalytic activity $[18,19]$. Therefore, the rational design and facile fabrication of heteroatom-doped carbon nanomaterials for efficient ORR remain a challenge.

Metal-organic frameworks (MOFs) are classified as a subclass of crystalline inorganic-organic materials due to their tunable nanostructure, versatile morphology, rich topology, and large porosity [20,21] and are extensively applied in various fields, such as gas storage and separation [22], drug delivery [23], heterogeneous catalysis [24,25], host-guest interaction [26], and proton conduction [27,28]. Among these, the zeolite-imidazole framework (ZIF-8) is formed by nitrogen-containing organic linkers (2-methylimidazole) connected with divalent zinc cations through coordination bonds. The calcined carbon materials from ZIF-8 precursors exhibit a high graphitization degree, high $\mathrm{N}$-doping content, and hierarchically porous structure and can effectively prevent particle agglomeration owing to their spatial features endowed by metal-based species $[29,30]$. These MOFderived nanomaterials usually retain their large specific surface

\footnotetext{
${ }^{1}$ Key Laboratory of Carbon Materials of Zhejiang Province, College of Chemistry and Materials Engineering, Wenzhou University, Wenzhou 325035, China

${ }^{2}$ Research Center of Applied Solid State Chemistry, Ningbo University, Ningbo 315211, China

${ }^{3}$ School of Materials and Energy, Guangdong University of Technology, Guangzhou 510006, China

* Corresponding author (email: jinjieqian@wzu.edu.cn)
} 
area and high porosity, thus exposing additional active catalytic sites and promoting rapid mass and electron transfer [31,32]. However, their micropores are easily blocked by electrolytes and in situ-generated gaseous products, which greatly reduce the active sites and hinder the mass transfer rate during electrochemical processes. To improve electrocatalytic activity and transfer efficiency, researchers have focused on MOF-derived three-dimensional (3D)-ordered porous carbon materials $[33,34]$.

In this study, a 3D-ordered interconnected porous carbon material codoped with $\mathrm{Fe}$ and $\mathrm{N}$ was successfully constructed with a silica-template method (Scheme 1). First, an ordered structure was assembled using ZIF-8 particles and $\mathrm{SiO}_{2}$ nanospheres as the carbon source and hard template, respectively, followed by the simple evaporation of supersaturated solvents and acid etching. After pyrolysis, the hierarchically ordered porous carbon network with the in situ-formed carbon nanotubes (CNTs), denoted as mFeNC-CNT, was prepared in a stepwise synthesis route involving $\mathrm{MOF}$ carbonization, $\mathrm{SiO}_{2}$ rearrangement, and carbon fusion. The obtained $\mathrm{mFeNC}-\mathrm{CNT}$ shows high nitrogen doping and graphitization degree that greatly improves its electrical conductivity. Its $3 \mathrm{D}$ porous structure can significantly enhance the accessibility of active sites, increase the contact area with the electrolytes, and promote mass and electron transfer efficiency. Owing to these advantages, the optimal $\mathrm{mFeNC}-\mathrm{CNT}$ with atomically dispersed $\mathrm{Fe}-\mathrm{N}_{x}$ active sites and Fe-based NPs exhibits excellent ORR performance and robust stability in an alkaline electrolyte. Furthermore, the $\mathrm{mFeNC}-\mathrm{CNT}$-based zinc-air battery displays a high open-circuit voltage of $1.556 \mathrm{~V}$ and a large peak power density of $108.0 \mathrm{~mW} \mathrm{~cm}^{-2}$, which are beneficial in expanding its practical energy-related applications.

\section{EXPERIMENTAL SECTION}

\section{Chemicals}

Zinc nitrate hexahydrate $\left(\mathrm{Zn}\left(\mathrm{NO}_{3}\right)_{2} \cdot 6 \mathrm{H}_{2} \mathrm{O}\right.$, analytical reagent (AR), Aladdin), 2-methylimidazole (2-HMeIm, 98\%), $\mathrm{NH}_{3} \cdot \mathrm{H}_{2} \mathrm{O}$ (AR, 25\%-28\%), tetraethyl orthosilicate (TEOS, 99\%), 1,2dichlorobenzene (DCB, 98\%, Aladdin), oleylamine (OAm, $\geq 98 \%$, Aldrich), urea $\left(\mathrm{CH}_{4} \mathrm{~N}_{2} \mathrm{O}, \mathrm{AR}, 99 \%\right.$, Aladdin), iron nitrate nonahydrate $\left(\mathrm{Fe}\left(\mathrm{NO}_{3}\right)_{3} \cdot 9 \mathrm{H}_{2} \mathrm{O}, \mathrm{AR}\right.$, Aladdin), hydrofluoric acid (HF, 40\%, Aladdin), methanol (MeOH, AR, 99.5\%), ethanol (EtOH, moisture content $\leq 0.3 \%$ from Aladdin), and $N, N$ dimethylformamide were used without further purification. $\mathrm{Pt} / \mathrm{C}$ (20 wt\%) and $5 \mathrm{wt} \%$ Nafion ionomer were acquired from AlfaAesar and Aldrich, respectively. All experiments were performed with high-purity $\mathrm{N}_{2}, \mathrm{O}_{2}$, Ar gas, and distilled water.

\section{Material preparation}

Synthesis of $\mathrm{SiO}_{2}$ particles

Hydrolyzed TEOS $(20 \mathrm{~mL})$ was dispersed into the mixture of ethanol (400 mL, $99.9 \%$ from $\mathrm{J} \& \mathrm{~K})$, distilled water $(28 \mathrm{~mL})$, and ammonium hydroxide $(16 \mathrm{~mL})$ with magnetic stirring of $120 \mathrm{r} \mathrm{min}^{-1}$ for $4 \mathrm{~h}$. After the solution color gradually changed from transparent to milky white, stirring was continued for another $12 \mathrm{~h}$. The white product was separated from the mixture, centrifuged several times, washed 2-3 times with ethanol, and dried overnight in an oven at $70^{\circ} \mathrm{C}$ to obtain $\mathrm{SiO}_{2}$ particles with a diameter of $\sim 140 \mathrm{~nm}$.

\section{Synthesis of ZIF-8 particles}

First, $1.2 \mathrm{~g}$ of $\mathrm{Zn}\left(\mathrm{NO}_{3}\right)_{2} \cdot 6 \mathrm{H}_{2} \mathrm{O}$ was dissolved into $50 \mathrm{~mL}$ of methanol $(\mathrm{MeOH})$ to obtain solution $\mathrm{A}$, and $3.25 \mathrm{~g}$ of 2 -HMeIm was added into another $50 \mathrm{~mL}$ methanol solution to generate solution $\mathrm{B}$. These two solutions were quickly mixed, stirred for $10 \mathrm{~min}$, and allowed to stand at room temperature for $5 \mathrm{~h}$ to obtain a milky white precipitate. Finally, the white product was subjected to centrifugal filtration, washed with methanol and ethanol several times, and dried overnight at $85^{\circ} \mathrm{C}$ to obtain the product.

\section{Synthesis of $\mathrm{NC@SiO}_{2}$ and $\mathrm{NC}$}

For preparation, $0.1 \mathrm{~g}$ of $\mathrm{SiO}_{2}$ (Fig. S1a) and $0.5 \mathrm{~g}$ of ZIF-8 (Fig. S2) were fully dissolved into $5 \mathrm{~mL}$ of $\mathrm{EtOH}$ with $0.3 \mathrm{~mL}$ of $\mathrm{DCB}$ and $60 \mu \mathrm{L}$ of OAm to obtain a uniform emulsion, which was then placed in an oven and heated at $100^{\circ} \mathrm{C}$ for $1 \mathrm{~h}$. After the ethanol had evaporated, a powder was obtained (Fig. S3a, b), which was further heated up to $1000^{\circ} \mathrm{C}$ at a ramp rate of

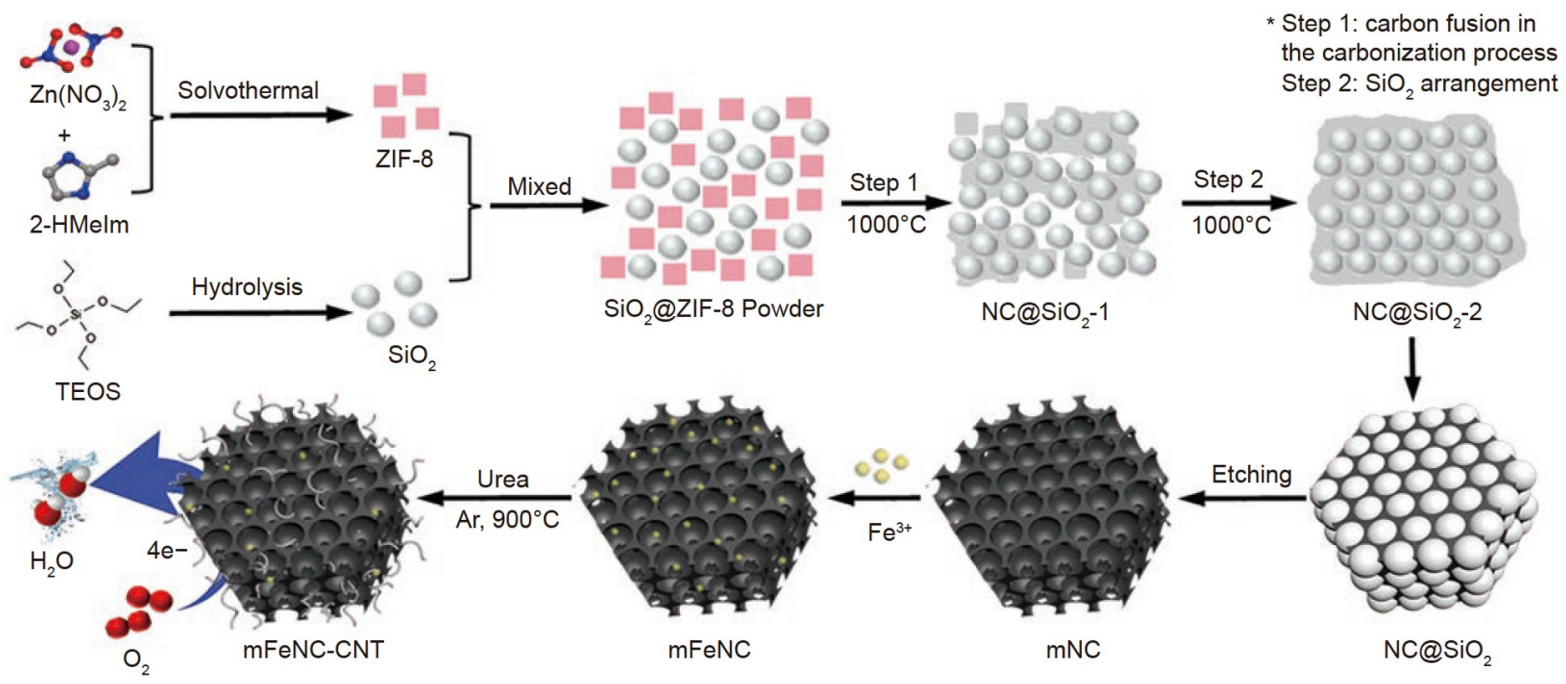

Scheme 1 Illustration of 3D-ordered hierarchically porous mFeNC-CNT from a silica-templated ZIF-8 precursor. 
$20^{\circ} \mathrm{C} \mathrm{min}^{-1}$ in the chemical vapor deposition (CVD) tubular furnace and maintained for $4 \mathrm{~h}$ in Ar atmosphere (100 standard cubic centimeter per minute $(\mathrm{sccm}))$. After the reaction was completed, the product was obtained after cooling to room temperature and labeled as $\mathrm{NC@SiO}_{2}$ (Fig. S3c, d). For $\mathrm{NC}$ preparation, the above ZIF- 8 particles were annealed at $1000^{\circ} \mathrm{C}$ in Ar atmosphere (100 sccm) for $4 \mathrm{~h}$.

\section{Synthesis of $m N C$ and $m F e N C$}

The NC@SiO ${ }_{2}$ mixture was subjected to HF etching to obtain the black powder, which was then labeled as $\mathrm{mNC}$. In brief, $20 \mathrm{mg}$ of $\mathrm{mNC}$ was further dissolved in $5 \mathrm{~mL}$ of $\mathrm{MeOH}$ and added into $100 \mathrm{mg}$ of $\mathrm{Fe}\left(\mathrm{NO}_{3}\right)_{3} \cdot 9 \mathrm{H}_{2} \mathrm{O}$. The mixture was stirred for $30 \mathrm{~min}$ at $500 \mathrm{r} \mathrm{min}^{-1}$, washed with ethanol, and dried. The obtained powder was heated up to $900^{\circ} \mathrm{C}$ at a heating rate of $20^{\circ} \mathrm{C} \mathrm{min}{ }^{-1}$ and maintained for $2 \mathrm{~h}$ to produce $\mathrm{mFeNC}$.

\section{Synthesis of $m F e N C-C N T$}

In brief, $20 \mathrm{mg}$ of $\mathrm{mFeNC}$ was placed on the left end of a $15-\mathrm{cm}$ quartz sleeve, and $200 \mathrm{mg}$ of urea was deposited on the other end. mFeNC-CNT was obtained at a yield of approximately $60 \%$ by annealing the quartz sleeve at $900^{\circ} \mathrm{C}$ with a heating rate of $20^{\circ} \mathrm{C} \mathrm{min}{ }^{-1}$ for $2 \mathrm{~h}$ in Ar atmosphere $(100 \mathrm{sccm})$. The repeatability of this experiment is excellent.

\section{Physical characterization}

The samples were scattered on clean silicon wafers, and those with poor conductivity were sprayed with gold for $30 \mathrm{~s}$. Scanning electron microscopy (SEM) images were obtained using a JSM-6700F field emission scanning electron microscope. For high-resolution transmission electron microscopy (HR-TEM) image and energy dispersive X-ray spectroscopy (EDS), the sample was ultrasonically dispersed in ethanol to generate a small amount of suspension on a micro-grid, which was then dried under an infrared lamp and subjected to a $200 \mathrm{kV}$ JEOL 6 JEM-2100F microscope. Powder X-ray diffraction (PXRD), Raman spectra, and X-ray photoelectron spectroscope (XPS) were collected by a Bruker D8 Advance using $\mathrm{Cu}$ Ka radiation $(\lambda=0.154 \mathrm{~nm})$, a Renishaw instrument (in Via-Reflex, $532 \mathrm{~nm}$, all reference Raman data were from the RRUFF Project website), and a Thermo Scientific ESCALAB 250, respectively. $\mathrm{N}_{2}$ isotherms were analyzed with the Micromeritics ASAP 2020 analyzer at liquid nitrogen temperature to calculate the BrunauerEmmett-Teller (BET) surface area, Langmuir surface area, and pore size distribution (PSD). Finally, thermogravimetric analysis was conducted using NETZSCH STA 449C with nitrogen flow at the heating rate of $10^{\circ} \mathrm{C} \mathrm{min}^{-1}$.

\section{Electrochemical analysis}

All data were collected in a traditional three-electrode cell within a Metrohm-Autolab (PGSTAT 302N) and/or CHI760E electrochemical using a carbon rod and a $\mathrm{Ag} / \mathrm{AgCl}$ electrode as the counter and reference electrodes, respectively. A glassy carbon rotating ring disk electrode (RRDE with a diameter of $5.6 \mathrm{~mm}$, geometric surface area of $0.2463 \mathrm{~cm}^{2}$ ) served as the working electrode in evaluating the ORR activity of these electrocatalysts. Hence, the catalyst was loaded at $0.4 \mathrm{mg} \mathrm{cm}^{-2}$ for the $0.1 \mathrm{~mol} \mathrm{~L}^{-1}$ $\mathrm{KOH}$ electrolyte. The working electrode was deposited with the electrocatalyst ink prepared as follows. The as-synthesized catalyst powder $(5 \mathrm{mg})$ was dispersed in the mixed solution of ethanol $(300 \mu \mathrm{L}), \mathrm{H}_{2} \mathrm{O}(150 \mu \mathrm{L})$, and Nafion solution (5 wt\%,
$50 \mu \mathrm{L}$ ), and the mixture was then ultrasonicated for $2 \mathrm{~h}$ to form a homogeneous ink. In brief, $20 \mu \mathrm{L}$ of the as-prepared droplet was deposited onto the surface of the glassy carbon electrode (GCE) and dried at room temperature. The electrocatalytic activities of catalysts toward ORR were measured at room temperature, and the measured potentials versus the reference electrode $\mathrm{Ag} / \mathrm{AgCl}$ were converted to reversible hydrogen electrode (RHE) potential using Nernst equation:

$$
\begin{aligned}
& E_{\mathrm{RHE}}=E_{\mathrm{Ag} / \mathrm{AgCl}}+0.059 \times \mathrm{pH}+E_{\mathrm{Ag} / \mathrm{AgCl}}^{\Theta}, \\
& \text { where } E_{\mathrm{Ag} / \mathrm{AgCl}}^{\Theta}=0.198 \mathrm{~V} .
\end{aligned}
$$

Cyclic voltammetry $(\mathrm{CV})$ experiments were performed with a scan rate of $5 \mathrm{mV} \mathrm{s}^{-1}$, and linear sweep voltammogram (LSV) was conducted at $5 \mathrm{mV} \mathrm{s}^{-1}$ under various rotation rates (100, $400,900,1600$, and $2500 \mathrm{r} \mathrm{min}^{-1}$ ) to obtain the polarization curves in $\mathrm{N}_{2}-/ \mathrm{O}_{2}$-saturated $0.1 \mathrm{~mol} \mathrm{~L}^{-1} \mathrm{KOH}$ solution. ORR reaction kinetics was evaluated using Koutechy-Levich (K-L) equation:

$1 / J=1 / J_{\mathrm{L}}+1 / J_{\mathrm{K}}$, $J_{\mathrm{L}}=0.2 n F C_{0} D_{0}^{2 / 3} v^{-1 / 6} \omega^{-1 / 2}=B \omega^{-1 / 2}$,

where $J$ is the experimental current density, $J_{\mathrm{L}}$ is the diffusionlimited current density, $J_{\mathrm{K}}$ is the kinetic current density, $\omega$ is the rotation speed in $\mathrm{r} \mathrm{min}^{-1}$ (round per min), $F$ is the Faraday constant $\left(96,485 \mathrm{C} \mathrm{mol}^{-1}\right), \mathrm{C}_{0}$ is the saturated $\mathrm{O}_{2}$ concentration $\left(1.21 \times 10^{-6} \mathrm{~mol} \mathrm{~cm}^{-3}\right), D_{0}$ is the diffusion coefficient of $\mathrm{O}_{2}$ in $0.1 \mathrm{~mol} \mathrm{~L}^{-1} \mathrm{KOH}\left(1.9 \times 10^{-5} \mathrm{~cm}^{2} \mathrm{~s}^{-1}\right)$, and $v$ is the kinetic viscosity $\left(0.01 \mathrm{~cm}^{2} \mathrm{~s}^{-1}\right)$.

For the evaluation of the active catalyst surface area, doublelayer capacitance $\left(C_{\mathrm{dl}}\right)$ was determined by measuring the $\mathrm{CV}$ plots in the region from 1.00 to $1.10 \mathrm{~V}$ versus $\mathrm{RHE}$ at various scan rates of $10-80 \mathrm{mV} \mathrm{s}^{-1}$ in $\mathrm{N}_{2}$-saturated $0.1 \mathrm{~mol} \mathrm{~L}^{-1} \mathrm{KOH}$ in the non-Faradaic potential region. After fitting the current density at $1.05 \mathrm{~V}$ versus RHE with various scan rates, the linear trend was observed and found to be equal to the slope of the linear $C_{\mathrm{d} \text { l. Alternating current }}$ (AC) impedance spectra were collected at frequencies ranging from 106 to $0.01 \mathrm{~Hz}$ at $0.7 \mathrm{~V}$ versus RHE. The following equations were used to calculate the electrons transferred number $(n)$ and the percentage of peroxide $\left(\mathrm{HO}_{2}{ }^{-} \%\right)$ released during ORR based on the disk current $\left(I_{\mathrm{d}}\right)$ and ring current $\left(I_{\mathrm{r}}\right)$. Here, the $\mathrm{H}_{2} \mathrm{O}_{2}$ collection coefficient $(N)$ at the ring in RRDE experiments was 0.37 .

$$
\begin{aligned}
& n=\frac{4\left|I_{\mathrm{d}}\right|}{\left|I_{\mathrm{d}}\right|+I_{\mathrm{r}} / N}, \\
& \mathrm{HO}_{2}^{-}(\%)=\frac{2 I_{\mathrm{r}} / N}{\left|I_{\mathrm{d}}\right|+I_{\mathrm{r}} / N} \times 100 \% .
\end{aligned}
$$

The chronoamperometry test was conducted at a constant potential of $0.475 \mathrm{~V}$ versus RHE with a rotation rate of $1600 \mathrm{r} \mathrm{min}^{-1}$ and a constant $\mathrm{O}_{2}$ flow. For the study of methanol crossover, the curves were recorded at the constant potential of $0.475 \mathrm{~V}$ versus $\mathrm{RHE}$ with the addition of $14 \mathrm{~mL}$ of methanol to $100 \mathrm{~mL}$ of $\mathrm{O}_{2}$-saturated electrolyte.

\section{Zn-air battery (ZAB) button}

In brief, $5 \mathrm{mg}$ of the catalyst was dispersed in a mixture of $500 \mu \mathrm{L}$ of ethanol and $50 \mu \mathrm{L}$ of Nafion to form a catalyst ink (mass loading of $\sim 1.0 \mathrm{mg} \mathrm{cm}{ }^{-2}$ ). The $\mathrm{ZAB}$ was tested in a $\mathrm{CHI760E}$ electrochemical workstation $(\mathrm{CH}$ Instruments, Shanghai). For the primary battery, a carbon paper electrode with the obtained catalyst was used as the cathode, a polished $\mathrm{Zn}$ 
foil was applied as the anode, and the electrolyte was set to $6 \mathrm{~mol} \mathrm{~L}^{-1} \mathrm{KOH}$. All ZABs were evaluated under ambient conditions. The discharge power density was calculated from the discharge polarized profiles using the following equation:

$P=U_{\mathrm{d}} \times J_{\mathrm{d}}$

where $P, U_{\mathrm{d}}$, and $J_{\mathrm{d}}$ are the discharge power density, discharge voltage, and discharge current density, respectively.

\section{Computational details}

The CASTEP module of Accelrys Materials Studio 8.0 software was used to geometrically optimize the structure of the constructed models of graphene $(\mathrm{G}), \mathrm{N}$-doped graphene $(\mathrm{G}-\mathrm{N})$, and graphene with $\mathrm{Fe}-\mathrm{N}_{x}$ sites $(\mathrm{G}-\mathrm{Fe}-\mathrm{N})$ composites with minimized energy, and the function was selected as Perdew-Burke-Ernzerhof in generalized gradient approximation. In this computation, the $G(001)$ surface was modeled in a $4 \times 4$ supercell, the Brillouin zone was sampled with $3 \times 4 \times 1 k$-points, and the cut-off energy was set at $300 \mathrm{eV}$. The adsorption energy $\left(E_{\mathrm{a}}\right)$ of $\mathrm{O}_{2}$ with different composites was calculated using the following equation:

$E_{\mathrm{a}}=E_{\mathrm{O}_{2}+\mathrm{sub}}-E_{\mathrm{O}_{2}}-E_{\mathrm{sub}}$,

where $E_{\mathrm{O}_{2}+\text { sub }}, E_{\mathrm{O}_{2}}$, and $E_{\text {sub }}$ are the energies of the G, G-N, and $\mathrm{G}-\mathrm{Fe}-\mathrm{N}$ substances combined with oxygen, oxygen molecule, and $\mathrm{G}, \mathrm{G}-\mathrm{N}$, or $\mathrm{G}-\mathrm{Fe}-\mathrm{N}$ substance, respectively.

\section{RESULTS AND DISCUSSION}

\section{Material characterization}

The nanostructure and morphology of silica-templated nanomaterials were first investigated via SEM/TEM. After the removal of these nanosized $\mathrm{SiO}_{2}$ spheres, a 3D-ordered structure composed of neatly arranged spherical macropores and interconnected carbons was obtained. Although the MOF structure has collapsed due to pyrolysis and etching, the resultant pores with a diameter of $80-120 \mathrm{~nm}$ are evenly distributed in the composite material (Fig. 1a inset). Compared with the initial $\mathrm{SiO}_{2}$ particle size of approximately $135 \mathrm{~nm}$, the obtained macropore is slightly smaller (Fig. S1b, d). The well-replicated hexagonal oriented close-packed structure of $\mathrm{SiO}_{2}$ is evident in these MOF-derived carbon nanomaterials, especially for $\mathrm{mNC}$ and mFeNC (Fig. 1a, and Figs S1c, S4, S5). As shown in Fig. 1b, the obtained $\mathrm{mFeNC}$ has also inherited the ordered macroporous morphology that can prevent infiltrating iron atoms from disrupting the porous carbon matrix. When pyrolyzed at $900^{\circ} \mathrm{C}$, carbon atoms were in situ generated via the cracking of hydrocarbon molecules and further deposited on the catalyst through diffusion. The grown multi-walled CNTs with a diameter of $10-20 \mathrm{~nm}$ and a length of up to several hundred nanometers are evenly distributed in Fig. 1c. Further details on $\mathrm{mFeNC}-\mathrm{CNT}$ nanostructures are shown in the HR-TEM images
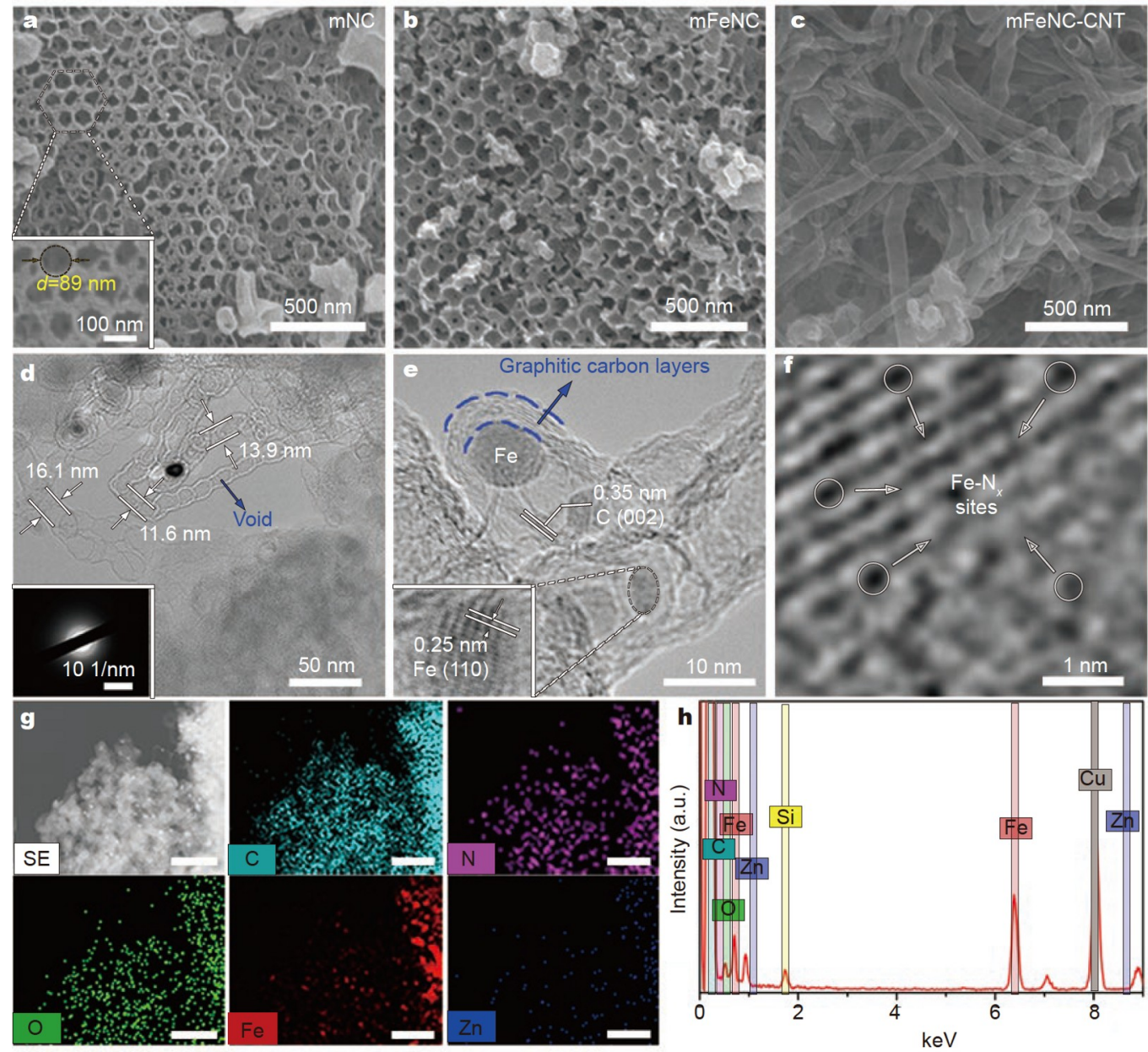

Figure 1 SEM images of (a) mNC, (b) mFeNC, and (c) mFeNC-CNT; (d, e, and f) TEM and HR-TEM images of mFeNC-CNT; inset of (d) is the corresponding selected area electron diffraction (SAED) pattern; (g) elemental mappings (scale bar: $200 \mathrm{~nm}$ ); (h) EDS pattern of mFeNC-CNT. 
in Fig. 1d, e and Figs S6, S7. The lattice fringes of multi-walled CNTs are in the size of $\sim 0.35 \mathrm{~nm}$, which corresponds to the (002) plane of the graphitic carbon. Approximately $0.25 \mathrm{~nm}$ spacings were also detected and reasonably ascribed to the metallic iron of (110) diffraction planes (Fig. 1e inset). Fig. If shows that the $\mathrm{Fe}$ atoms are embedded into the $\mathrm{N}$-doped carbon framework to generate thermodynamically stable $\mathrm{Fe}-\mathrm{N}_{x}$ sites. In particular, mFeNC-CNT presents the highly graphitized $\mathrm{N}$ doped carbon layers anchored by iron atoms, which bring a wealth of structural defects. The high-angle annular dark-field scanning TEM image and the corresponding element map of mFeNC-CNT illustrate the uniform distribution of $\mathrm{C}, \mathrm{N}, \mathrm{O}, \mathrm{Fe}$, and residual $\mathrm{Zn}$ species (Fig. 1g). EDS confirmed the chemical composition as follows: C (89.18 wt\%), N (4.27 wt\%), $\mathrm{O}$ (4.90 wt\%), Zn (0.13 wt\%), Fe (0.74 wt\%), and Si (0.87 wt\%) (Fig. $1 \mathrm{~h}$ and Table S1). Therefore, these macroporous carbon nanomaterials allow the reactants to effectively penetrate into the pores and fully contact the active sites for an improved application [35].

The surface area and pore information of pristine ZIF-8 and its derivatives were further analyzed by $\mathrm{N}_{2}$ isotherms. All materials behave as type IV isotherms with hysteresis loops that imply a rich mesoporous structure [36]. After high-temperature pyrolysis, the carbonized N-doped $\mathrm{NC}\left(594.8 \mathrm{~m}^{2} \mathrm{~g}^{-1}\right.$, $\left.1.14 \mathrm{~cm}^{3} \mathrm{~g}^{-1}\right)$ retains abundant micropores from the initial ZIF-8 $\left(1304.3 \mathrm{~m}^{2} \mathrm{~g}^{-1}, 1.49 \mathrm{~cm}^{3} \mathrm{~g}^{-1}\right)$. This finding can be attributed to the overall structure of MOF precursors undergoing a significant collapse during calcination. As a result, some micropores are blocked, and specific surface area and total pore volume are reduced. The BET-specific surface areas of $\mathrm{mNC}, \mathrm{mFeNC}$, and $\mathrm{mFeNC}-\mathrm{CNT}$ are $396.7,341.7$, and $497.9 \mathrm{~m}^{2} \mathrm{~g}^{-1}$, respectively, and their total pore volumes are $1.09,1.04$, and $1.22 \mathrm{~cm}^{3} \mathrm{~g}^{-1}$, respectively (Fig. 2a, b and Table S2). mFeNC-CNT has a higher specific surface area than $\mathrm{mNC}$ and $\mathrm{mFeNC}$ due to its abundant CNTs. On one hand, when silica nanospheres are utilized to create large pores, macropores $(>50 \mathrm{~nm})$ tend to replace some parts of the microporous structure and thus reduce the surface area. On the other hand, the ordered mesopores and macropores with open interconnections significantly increase the permeability of the electrolyte, promote the ion diffusion rate, and provide additional catalytic sites [37,38]. PXRD analyses were conducted to prove whether iron species exist in the $3 \mathrm{D}$-ordered carbon. The results show that $\mathrm{mFeNC}$ and $\mathrm{mFeNC}-\mathrm{CNT}$ exhibit two weak peaks at 2 -theta of $43.5^{\circ} / 44.8^{\circ}$ indexed to the $\mathrm{Fe}_{3} \mathrm{C}$ (102) and metallic Fe (110) plane, respectively (Fig. 2c). Therefore, ultrafine Fe particles are uniformly dispersed in the carbon matrix without severe aggregation. Raman spectra were then used to illustrate the graphitization degree as shown in Fig. 2d. A couple of characteristic peaks appear at 1331 and $1576 \mathrm{~cm}^{-1}$, which belong to the disordered carbon $\mathrm{D}$ band with defect sites and the $G$ band reflecting the plane vibration of graphite, respectively [39]. The $\mathrm{D} / \mathrm{G}$-band peak intensity ratios $\left(I_{\mathrm{D}} / I_{\mathrm{G}}\right)$ are $1.02,1.01,1.01$, and 0.992 for $\mathrm{NC}, \mathrm{mNC}, \mathrm{mFeNC}$, and mFeNC$\mathrm{CNT}$, respectively. The high graphitization degree for mFeNCCNT enhances the corrosion resistance and thus significantly improves the structural stability of the catalyst [40]. Therefore, $\mathrm{mFeNC}-\mathrm{CNT}$ exhibits an ordered mesoporous structure, a large specific surface area, and rich $\mathrm{Fe}-\mathrm{N}_{x}$ active sites and CNTs. These advantages render it an efficient electrocatalyst.

XPS was further utilized to characterize the doped elements and bonding configurations (Fig. 3 and Fig. S8). The full survey spectra reveal the coexistence of $\mathrm{C}, \mathrm{N}, \mathrm{O}, \mathrm{Zn}$, and Fe elements in $\mathrm{mFeNC}$ and $\mathrm{mFeNC}-\mathrm{CNT}$. The fuzzy Fe signal can be attributed to its low initial concentration, and the low content of $\mathrm{Zn}$
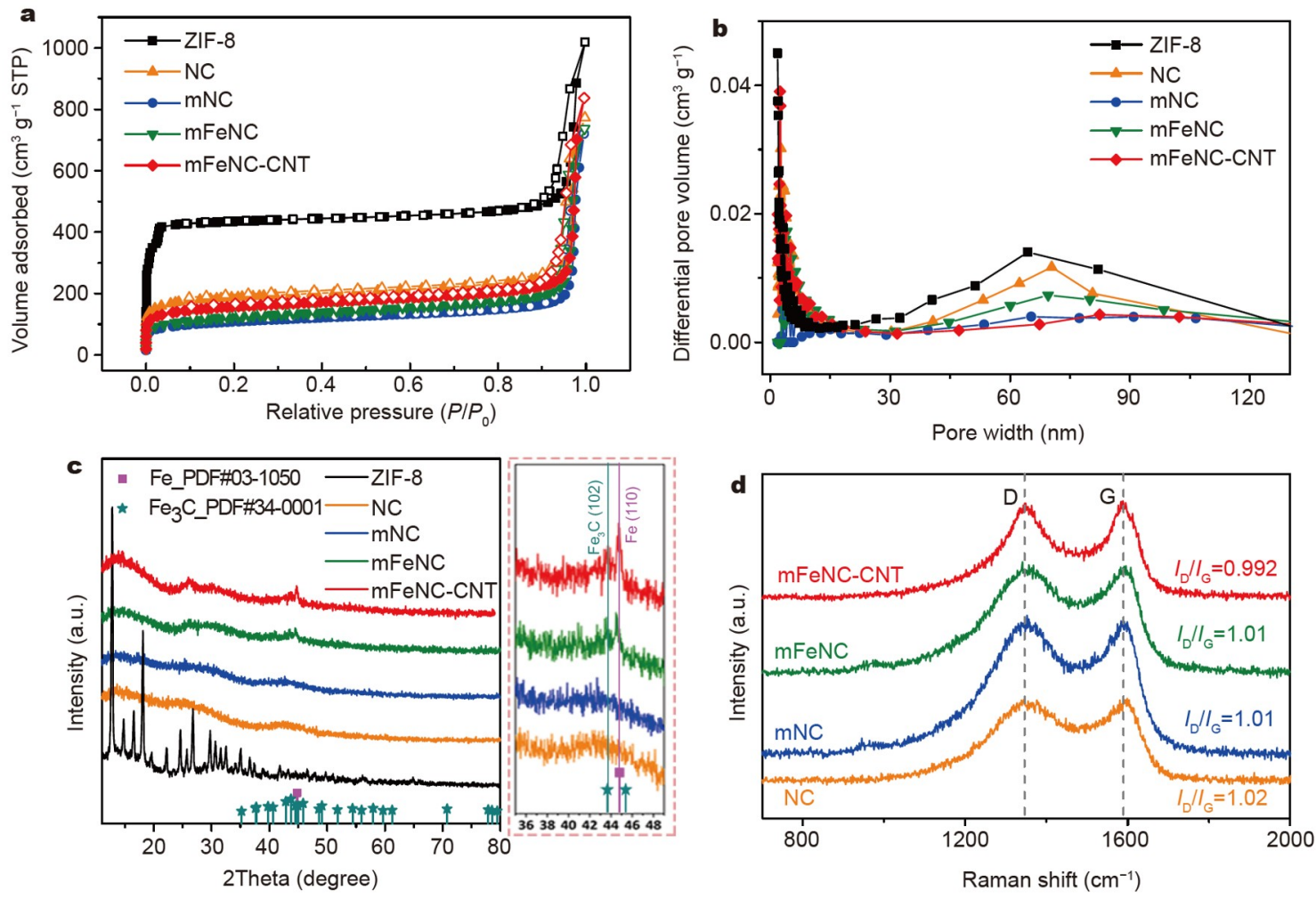

Figure 2 (a) $\mathrm{N}_{2}$ isotherms, (b) PSD, and (c) PXRD patterns of ZIF-8, NC, mNC, mFeNC, and mFeNC-CNT; (d) Raman spectra of ZIF-8-derived carbons. 
indicates that most of the zinc species have been removed (Fig. $3 \mathrm{a}$ and Table S3). By contrast, $\mathrm{mNC}$ has no Fe peaks in accordance with the elemental mapping results (Fig. S4). The C $1 \mathrm{~s}$ spectra can be fitted into five separate peaks that belong to $\mathrm{C}-\mathrm{C} \mathrm{sp}{ }^{2}(284.7 \mathrm{eV}), \mathrm{C}-\mathrm{C} \mathrm{sp}{ }^{3}(285.6 \mathrm{eV}), \mathrm{C}-\mathrm{O} / \mathrm{C}-\mathrm{N}(286.7 \mathrm{eV})$, $\mathrm{C}=\mathrm{O} / \mathrm{C}=\mathrm{N}(287.6 \mathrm{eV})$, and $\mathrm{O}=\mathrm{C}-\mathrm{O}(288.9 \mathrm{eV})$ in Fig. 3b. The main percentage of carbon is ascribed to $\mathrm{C}=\mathrm{C} \mathrm{sp}^{2}$, which is indicative of the successful formation of graphitic carbons [41]. As shown in Fig. $3 c$, the high-resolution $\mathrm{N}$ 1s spectrum of $\mathrm{mNC}$ can be deconvoluted into four main peaks at 398.3, 399.7, 400.8, and $402.2 \mathrm{eV}$ corresponding to pyridinic- $\mathrm{N}$, pyrrolic- $\mathrm{N}$, graphitic-N, and oxidized-N, respectively. Pyridinic-N and graphitic- $\mathrm{N}$ are the main active components in the two catalysts, and graphitic- $\mathrm{N}$ can effectively weaken $\mathrm{O}-\mathrm{O}$ bonds $[42,43]$. In addition, the $\mathrm{N}$ 1s spectra of $\mathrm{mFeNC}$ and $\mathrm{mFeNC}-\mathrm{CNT}$ show an additional fitting peak at $399.0 \mathrm{eV}$ for $\mathrm{Fe}-\mathrm{N}_{x}$ species (Fig. S8) [44]. mFeNC-CNT exhibits a relatively low content of pyridinic$\mathrm{N}$ due to the selective cleavage of pyridinic- $\mathrm{N}$ bonds that provide additional coordination sites for the central $\mathrm{Fe}$ atoms to form $\mathrm{Fe}$ $\mathrm{N}_{x}$ active sites. For $\mathrm{O} 1 \mathrm{~s}$, two characteristic subpeaks of $\mathrm{C}-\mathrm{O}$ $(532.7 \mathrm{eV})$ and $\mathrm{M}-\mathrm{O}(530.3 \mathrm{eV})$ are clearly differentiated (Fig. 3d) [43]. The high-resolution $\mathrm{Zn} 2 \mathrm{p}$ spectra are mainly assigned to $\mathrm{Zn} 2 \mathrm{p}_{3 / 2}(1022.05$ and $1023.06 \mathrm{eV})$ and $\mathrm{Zn} 2 \mathrm{p}_{1 / 2}$ (1045.0 and $1045.85 \mathrm{eV}$ ) in Fig. 3e [45]. Meanwhile, the highresolution Fe $2 p$ spectra can be divided into three pairs of peaks, thereby confirming that iron atoms have been successfully incorporated (Fig. 3f). Herein, two peaks centered at 710.6 and $723.8 \mathrm{eV}$ are attributed to $\mathrm{Fe} 2 \mathrm{p}_{3 / 2}$ and $\mathrm{Fe} 2 \mathrm{p}_{1 / 2}$, respectively, and a couple of peaks at 712.9 and $727.1 \mathrm{eV}$ correspond to the $\mathrm{Fe}-\mathrm{N}_{x}$ configuration. These results verify the formation of an atomically iron environment. The two remaining subpeaks at 718.2 and $733.6 \mathrm{eV}$ are ascribed to the satellite peaks for Fe elements [46]. In congruence with the PXRD analysis, mFeNC-CNT consists of rich graphitic carbons and abundant $\mathrm{Fe}-\mathrm{N}_{x}$ sites that are indispensable in adjusting the electronic structure and facilitating electron transport to efficiently catalyze subsequent electrochemical reactions.

\section{ORR performance of electrocatalysts}

The electrocatalytic ORR activity was first evaluated by $\mathrm{CV}$ in the $\mathrm{KOH}$ electrolyte. As shown in Fig. 4a, all catalysts exhibit clear cathodic peaks that indicate ORR under $\mathrm{O}_{2}$-saturated conditions. The ORR peak reaches $0.93 \mathrm{~V}$ for $\mathrm{mFeNC}-\mathrm{CNT}$, which is even higher than that of the commercial $20 \mathrm{wt} \% \mathrm{Pt} / \mathrm{C}$ $(0.92 \mathrm{~V})$ and other control samples, including $\mathrm{NC}(0.76 \mathrm{~V})$, $\mathrm{mNC}(0.77 \mathrm{~V})$, and $\mathrm{mFeNC}(0.89 \mathrm{~V})$. LSV was further conducted to compare their catalytic performances in terms of onset potential $\left(E_{\text {onset }}\right)$, half-wave potential $\left(E_{1 / 2}\right)$, and limiting diffusion current density ( $J_{\mathrm{L}}$, Fig. 4b, Figs S9, S10, and Table S4). mFeNC-CNT shows the best performance with $E_{\text {onset }}$ and $E_{1 / 2}$ of 1.029 and $0.908 \mathrm{~V}$, respectively. Its $J_{\mathrm{L}}$ value is $5.589 \mathrm{~mA} \mathrm{~cm}^{-2}$, which is superior to that of $\mathrm{Pt} / \mathrm{C} \quad(1.01 \mathrm{~V}, 0.887 \mathrm{~V}$, $5.581 \mathrm{~mA} \mathrm{~cm}^{-2}$ ). According to the polarization curves obtained under different rotation rates, the linear relationship of the K-L diagram reflects a first-order reaction kinetics of the electron transfer number and dissolved oxygen concentration of the catalyst (Fig. 4c) [47]. As shown in Fig. 4d, the average electron number $(n)$ is 3.95 for mFeNC-CNT, which is slightly higher than that of $\mathrm{Pt} / \mathrm{C}$ (3.94). Therefore, $\mathrm{mFeNC}-\mathrm{CNT}$ traverses the four-electron pathway to form $\mathrm{H}_{2} \mathrm{O} / \mathrm{OH}^{-}$from $\mathrm{O}_{2}$ molecules with the lowest $\mathrm{H}_{2} \mathrm{O}_{2}$ yield $(<5 \%)$. As shown in Fig. $4 \mathrm{e}, \mathrm{mFeNC}$ CNT has a smaller Tafel slope of $56.1 \mathrm{mV} \mathrm{dec}^{-1}$ than Pt/C (57.2), $\mathrm{mFeNC}$ (58.8), $\mathrm{mNC}$ (65.8), and $\mathrm{NC}$ (67.3), and therefore provides the fastest electron transfer rate. The influence of different catalysts on electrochemical ORR performance was further investigated by electrochemical impedance spectroscopy (EIS). In general, a low charge transfer resistance $\left(R_{\mathrm{ct}}\right)$ corresponds to a fast charge transfer at the electrolyte interface. Compared with
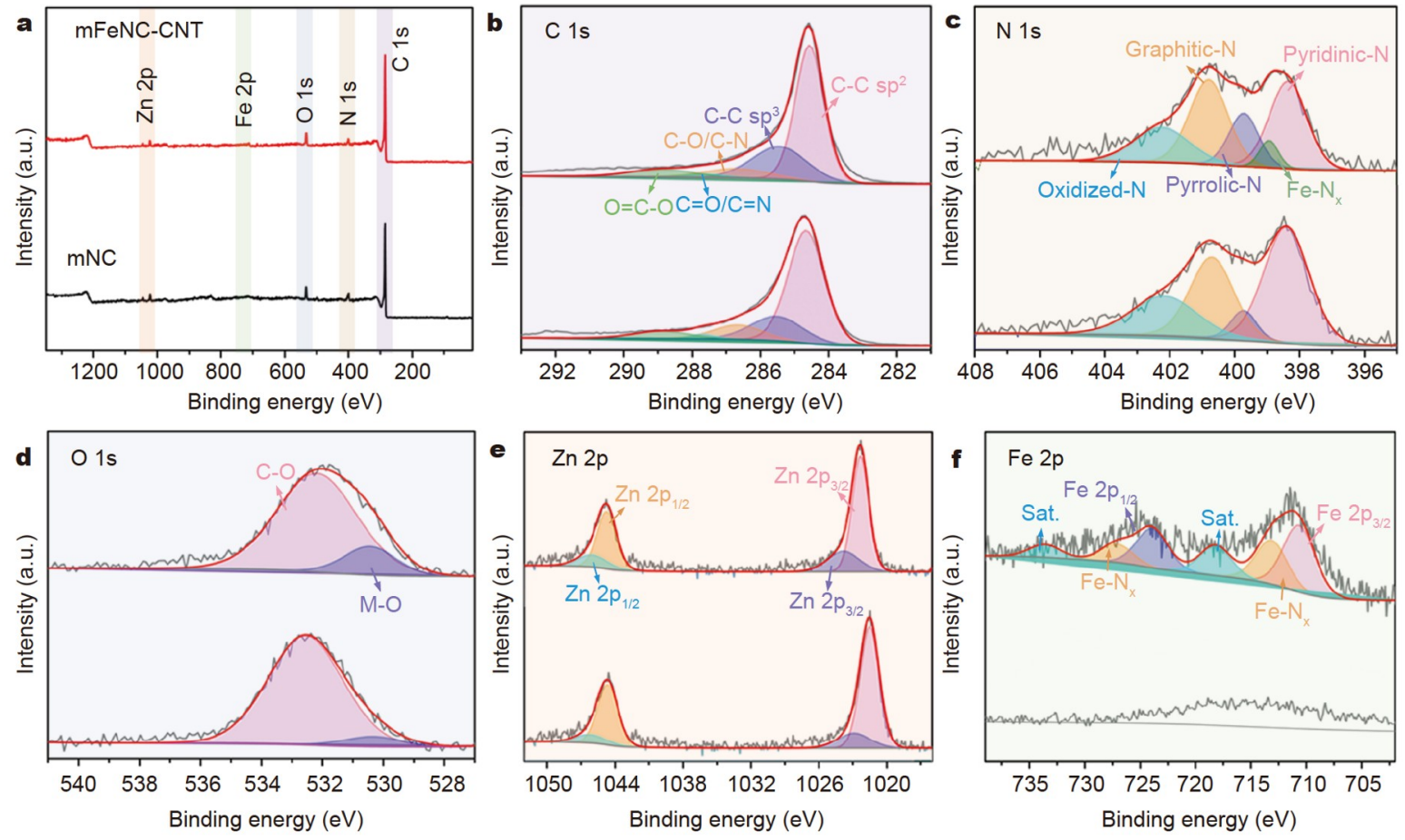

Figure 3 (a) Full XPS spectra of mNC (black line) and mFeNC-CNT (red line); deconvoluted spectra of (b) C 1s, (c) N 1s, (d) O 1s, (e) Zn 2p, and (f) Fe 2p for the mNC (bottom line) and mFeNC-CNT (top line). 

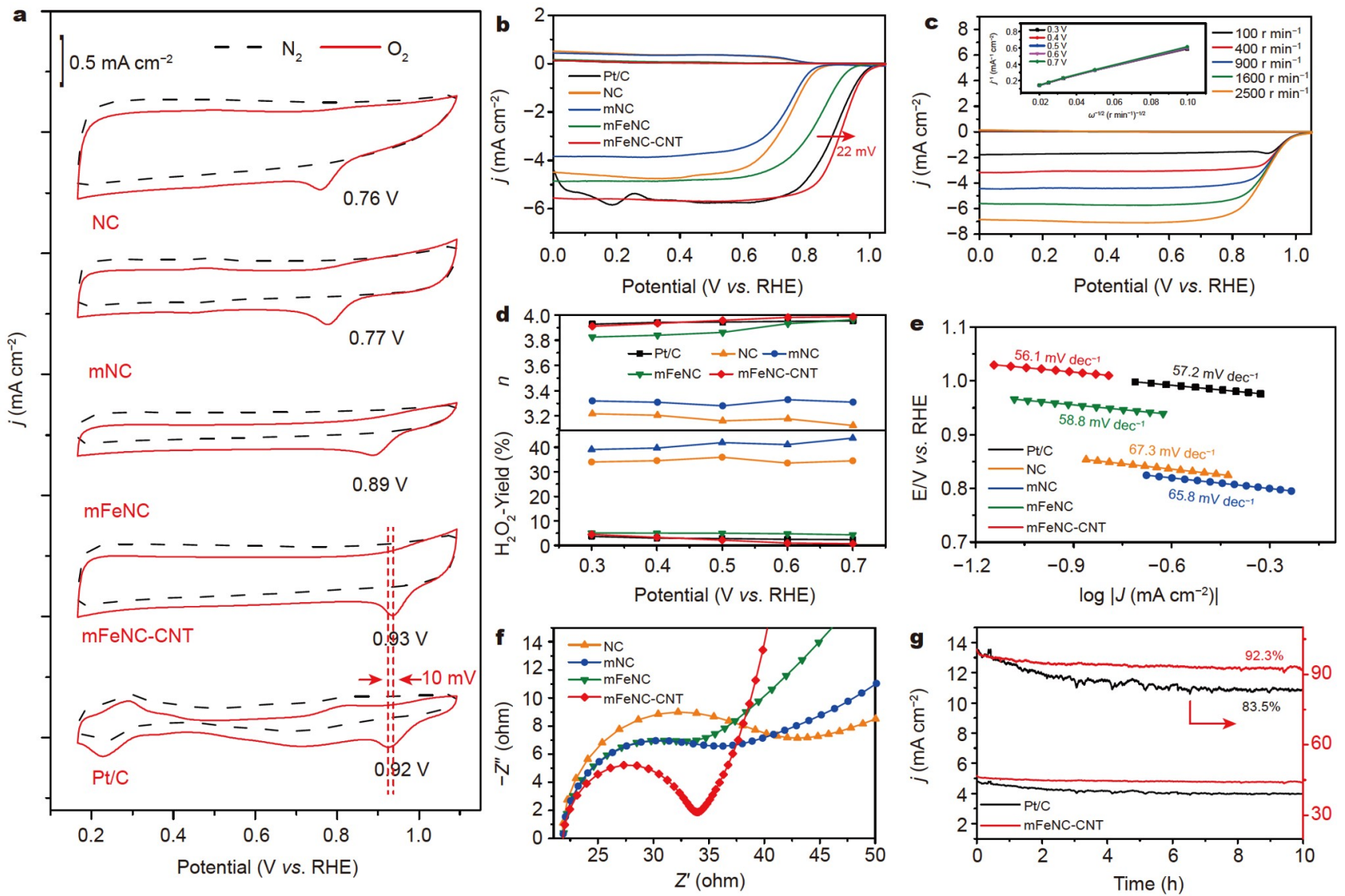

Figure 4 (a) $\mathrm{CV}$ curves in $\mathrm{N}_{2}-/ \mathrm{O}_{2}$-saturated solutions; (b) LSV curves at $1600 \mathrm{r} \mathrm{min}^{-1}$; (c) LSV curves and its K-L plots as an inset for mFeNC-CNT; (d) transferred $n$ and $\mathrm{H}_{2} \mathrm{O}_{2}$ yield; (e) Tafel plots; (f) EIS profiles; (g) stability evaluation at $0.6 \mathrm{~V}$.

$\mathrm{Pt} / \mathrm{C}(14.381 \Omega)$, NC $(25.889 \Omega)$, $\mathrm{mNC}(22.242 \Omega)$, and $\mathrm{mFeNC}$ $(16.644 \Omega)$, the optimal mFeNC-CNT exhibits the lowest charge transfer resistance $\left(R_{\mathrm{ct}}=12.146 \Omega\right)$ (Fig. $4 \mathrm{f}$ and Table S5) that is beneficial to accelerate the oxygen transfer and improve the efficiency of the electrocatalytic reaction. In addition, $\mathrm{mFeNC}$ CNT has the largest slope at the low-frequency regions and therefore has the fastest diffusion rate and lowest Warburg impedance (Figs S11 and S12). On the basis of the CV curves, the electrochemical double-layer capacitance $\left(C_{\mathrm{dl}}\right)$ of mFeNCCNT is $4.77 \mathrm{mF} \mathrm{cm}^{-2}$, which is higher than that of other control catalysts (Fig. S13). Given that long-term durability is important for practical applications, the chronopotential curve was further tested for mFeNC-CNT and $\mathrm{Pt} / \mathrm{C}$ as shown in Fig. $4 \mathrm{~g}$ and Figs S14, S15. Although both materials show weak current density, mFeNC-CNT has a high retention of $92.3 \%$ and thus is more stable than $\mathrm{Pt} / \mathrm{C}(83.5 \%)$ after $10 \mathrm{~h}$ at $0.6 \mathrm{~V}$. As shown in Fig. S16, the current density of mFeNC-CNT hardly decreases after the addition of $3.0 \mathrm{~mol} \mathrm{~L}^{-1} \mathrm{MeOH}$, whereas $\mathrm{Pt} / \mathrm{C}$ shows a poor methanol resistance. In summary, the obtained mFeNCCNT has a $3 \mathrm{D}$-ordered porous carbon framework and catalytically grown CNTs that synergistically contribute to surface sorption and oxygen electroreduction.

\section{ZAB performance}

Owing to its excellent electrocatalytic performance, the hierarchically porous mFeNC-CNT was used to assemble ZABs for practical applications [48-50]. As shown in Fig. 5a, the catalystsupported carbon paper was used as the air cathode, the polished zinc plate as the anode, and $6.0 \mathrm{~mol} \mathrm{~L}^{-1} \mathrm{KOH}$ as the electrolyte. During discharge, the metal plate undergoes oxidation to generate $\mathrm{Zn}(\mathrm{OH})_{4}{ }^{2-}$ complex, and the carbon paper catalyzes the oxygen reduction at the interface through the loaded catalyst. For comparison, two ZABs composed of $\mathrm{Pt} / \mathrm{C}$ or mFeNC-CNT were prepared. The mFeNC-CNT-based ZAB displays an opencircuit voltage as high as $1.556 \mathrm{~V}$ at $900 \mathrm{~s}$ and a peak power density of $108.0 \mathrm{~mW} \mathrm{~cm}^{-2}$, which are higher than those of $\mathrm{Pt} / \mathrm{C}$ (1.492 $\mathrm{V}$ and $99.3 \mathrm{~mW} \mathrm{~cm}^{-2}$ ) (Fig. 5b, c and Fig. S17). Fig. 5d illustrates that the constant current discharge curve of the mFeNC-CNT-based ZAB shows a fast dynamic response and gradually decreases from 5 to $100 \mathrm{~mA} \mathrm{~cm}^{-1}$. Its specific capacity is $797.7 \mathrm{~mA} \mathrm{~h} \mathrm{~g}^{-1}$ at $10 \mathrm{~mA} \mathrm{~cm}{ }^{-2}$ for $10 \mathrm{~h}$, which is higher than that of $\mathrm{Pt} / \mathrm{C}$ (732.5 $\mathrm{mA} \mathrm{h} \mathrm{g}^{-1}$, Fig. 5e). Two of the as-prepared ZABs were used in a series circuit to successfully provide a continuous power supply for a light-emitting diode light with a "Qlab" character (Fig. 5f). mFeNC-CNT shows a remarkable performance that could be attributed to the difference in ORR among different catalysts as follows: (i) the hierarchically porous structure obtained by the $\mathrm{SiO}_{2}$ template increases the mass transfer rate, provides favorable reaction kinetics, and extends the contact area between the electrolyte and the active material; (ii) the abundant active sites of $\mathrm{N}$ species and $\mathrm{Fe}-\mathrm{N}_{x}$ calcined from $3 \mathrm{D}$-ordered MOF structure can achieve a satisfactory ORR response similar to noble metals; (iii) the interwoven CNTs formed by $\mathrm{N}$-containing urea can produce numerous defects and increase the specific surface area, thus providing a rapid conductive path for charge transport and consequently facilitating 

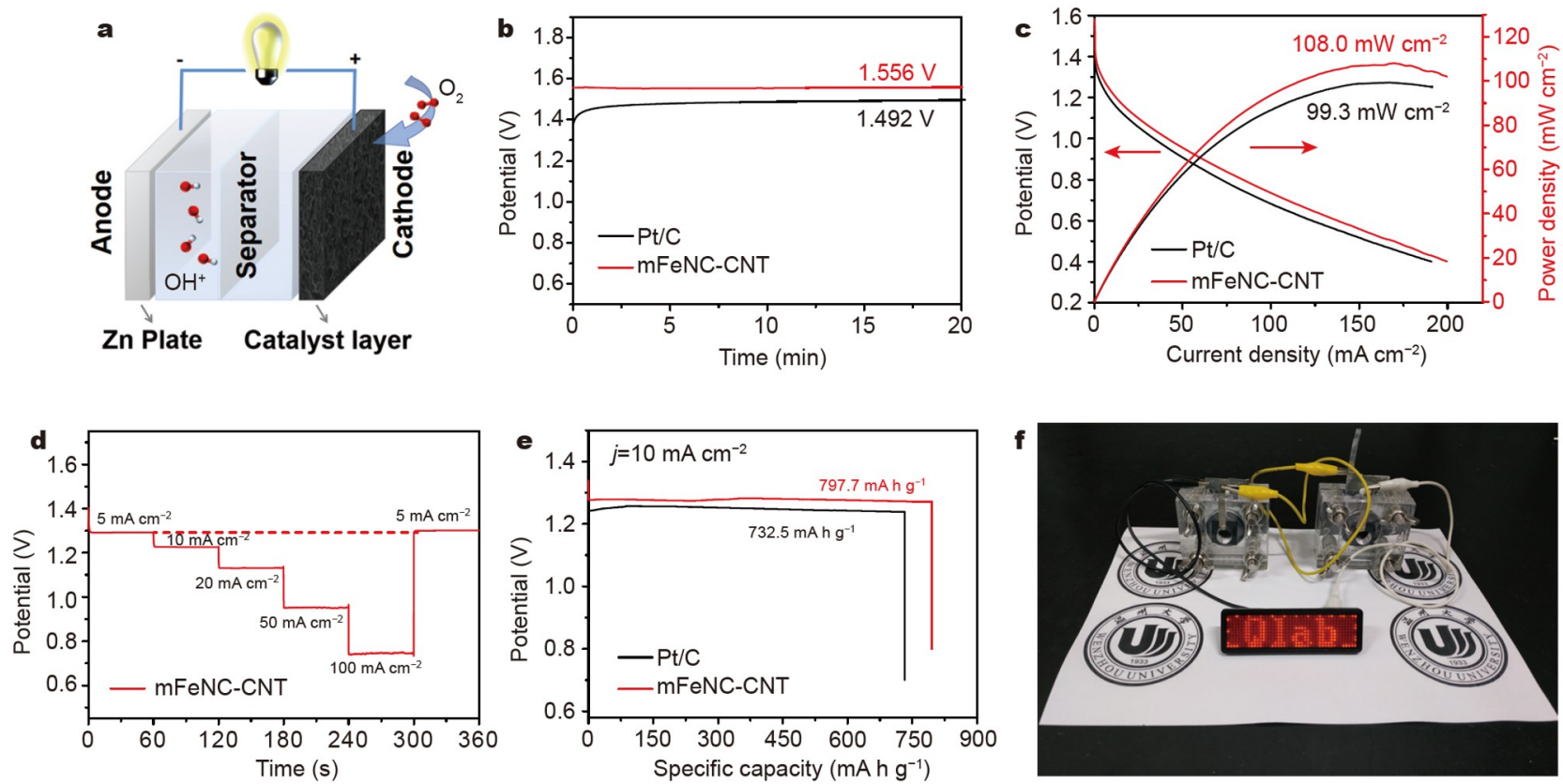

Figure 5 (a) Illustration of a ZAB, (b) open-circuit voltages, (c) polarization and power density curves, (d) discharge curves at various current densities, and (e) galvanostatic discharge curves at $10 \mathrm{~mA} \mathrm{~cm}^{-2}$ of $\mathrm{mFeNC}-\mathrm{CNT}$ and $\mathrm{Pt} / \mathrm{C}$ based ZABs. (f) Photograph of two ZABs in series.

oxygen reduction. Therefore, mFeNC-CNT shows an ORR electrocatalytic performance that is comparable to the state-ofthe-art $\mathrm{Pt} / \mathrm{C}$ and has huge application potential in practical power devices.

\section{Theoretical calculations}

Theoretical calculations were conducted to illustrate the adsorption energy of $\mathrm{O}_{2}$ on the surface of various catalysts and further reveal the promoting effect of $\mathrm{Fe}-\mathrm{N}_{x}$ sites on the elec- trocatalytic ORR. Three different carbon structures were formed, namely, graphene $(\mathrm{G}), \mathrm{N}$-doped graphene $(\mathrm{G}-\mathrm{N})$, and graphene with $\mathrm{Fe}-\mathrm{N}_{x}$ sites $(\mathrm{G}-\mathrm{Fe}-\mathrm{N})$. Given that the main configurations of $\mathrm{Fe}-\mathrm{N}_{x}$ species are generally effective as active sites, the most thermodynamically stable $\mathrm{Fe}-\mathrm{N}_{4}$ centers were reasonably selected as the model. According to the adsorption energy $\left(E_{\mathrm{a}}\right), \mathrm{G}-\mathrm{Fe}$ $\mathrm{N}$ exhibits a higher $\mathrm{O}_{2}$ adsorption capacity $(-4.325 \mathrm{eV})$ than $\mathrm{G}(-0.309 \mathrm{eV})$ and $\mathrm{G}-\mathrm{N}(-0.504 \mathrm{eV})$ (Fig. 6a). This finding can be attributed to the electron density of the delocalized $\pi$ band in

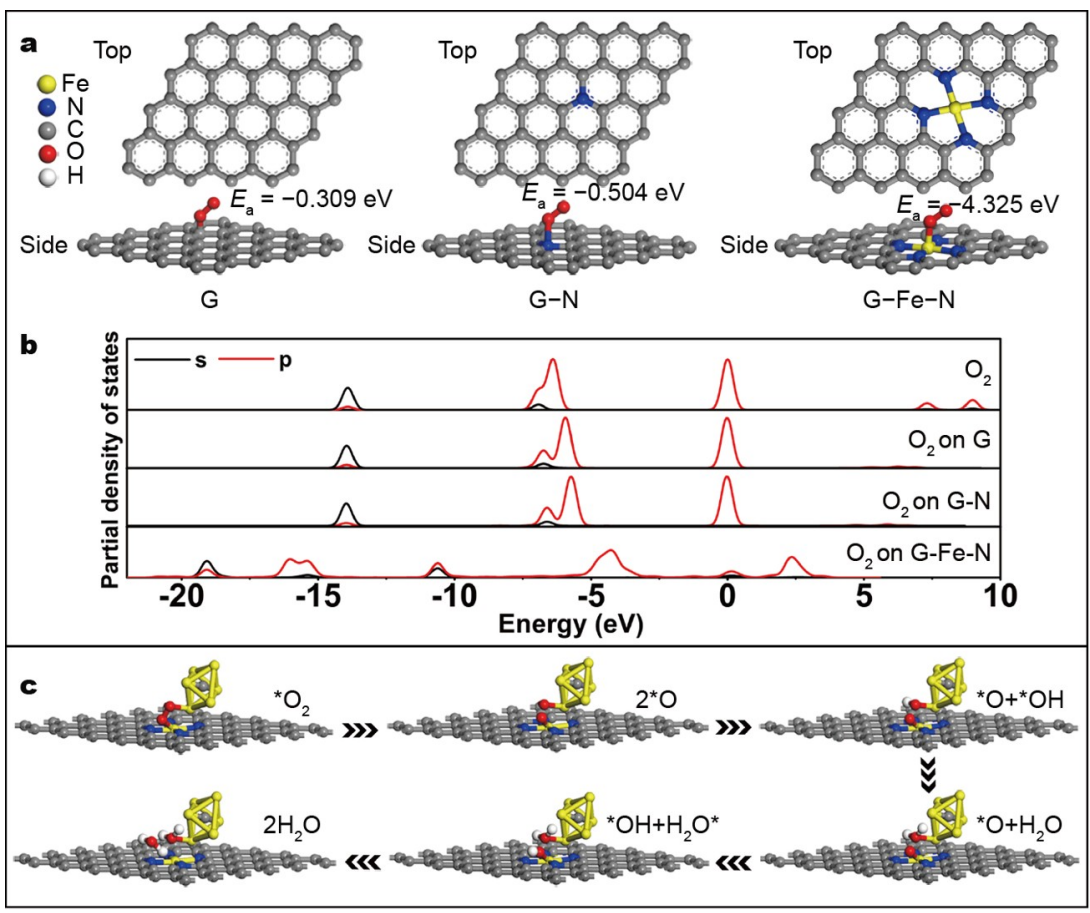

Figure 6 (a) Geometrically optimized structures and (b) PDOS curves after $\mathrm{O}_{2}$ adsorption on G, G-N, and G-Fe-N; (c) optimized adsorption configurations of ORR intermediates on the G-Fe-N/Fe interface. 
the carbon plane and the $\mathrm{d}$ orbital of $\mathrm{Fe}$ ions in the $\mathrm{Fe}-\mathrm{N}_{4}$ site. Meanwhile, the calculated partial density of states (PDOS) diagram shows that compared with pure $\mathrm{O}_{2}$ molecules, G-Fe-N has a significantly broadened energy due to valence hybridization. Owing to the interaction, some of the charges in the $\mathrm{O}_{2}$ molecule are transferred to G-Fe-N (Fig. 6b). In this case, Fe NPs and a small amount of $\mathrm{Fe}_{3} \mathrm{C}$ are simultaneously mixed in the graphitic carbons, as evidenced by PXRD in Fig. 2c. The synergistic effect between $\mathrm{Fe}-\mathrm{N}_{x}$ sites and $\mathrm{Fe} \mathrm{NPs} / \mathrm{Fe}_{3} \mathrm{C}$ (denoted as G-Fe-N/Fe) further improves the $\mathrm{O}_{2}$ adsorption capacity, and the detailed catalytic process is illustrated in Fig. 6c. First, the metal cluster and $\mathrm{G}-\mathrm{Fe}-\mathrm{N}$ layer will adsorb the activate $\mathrm{O}_{2}$. Owing to the interfacial $\mathrm{Fe}$ atoms, both ends of $* \mathrm{O}_{2}$ can be adsorbed on the $\mathrm{Fe}$ atoms of $\mathrm{Fe}-\mathrm{N}_{x}$ and $\mathrm{Fe}$ cluster [51]. Second, ${ }^{*} \mathrm{O}_{2}$ will be further reduced to $* \mathrm{O}$ and $* \mathrm{OH}$ radicals. Third, the over-oxidized $\mathrm{Fe}$ sites will be reversely reduced and will release one $\mathrm{H}_{2} \mathrm{O}$ molecule. Finally, due to the synergistic effect, the d-band center of the $\mathrm{Fe}$ atom in the adjacent $\mathrm{Fe}-\mathrm{N}_{x}$ will weaken the adsorption energy of the $* \mathrm{O}$ species to easily reduce them to $\mathrm{H}_{2} \mathrm{O}$. This simulation confirms that $\mathrm{Fe} \mathrm{NPs} / \mathrm{Fe}_{3} \mathrm{C}$ cooperates with $\mathrm{Fe}-\mathrm{N}_{x}$ sites to promote the activation of $\mathrm{O}_{2}$, the rupture of $\mathrm{O}=\mathrm{O}$ bonds, and the reduction and removal of intermediates in the ORR.

\section{CONCLUSION}

A 3D-ordered porous mFeNC-CNT with abundant CNTs and $\mathrm{Fe}-\mathrm{N}_{x}$ sites was successfully prepared using a simple templateetching method. Its interconnected pore structure can promote the penetration of oxygen and electrolyte with small diffusion resistance. After being calcinated, the hierarchically porous carbon nanomaterial can prevent the agglomeration of ironbased particles, and the in situ grown CNTs help improve the conductivity of the electrode. Owing to these advantages, the optimal mFeNC-CNT exhibits excellent ORR performance with a high $E_{\text {onset, }}$, a large $J_{\mathrm{L}}$, and a small Tafel slope, as confirmed by the theoretical calculations. Furthermore, the assembled ZAB based on mFeNC-CNT presents excellent open-circuit voltage, high peak power density, and high energy and shows satisfactory long-term stability and methanol resistance for practical applications. These MOF-derived porous carbon nanomaterials provide a new pathway to create cost-effective, robust, and highly active ORR catalysts for efficient energy storage and conversion systems.

Received 3 November 2021; accepted 14 December 2021; published online 28 February 2022

1 Dai L, Xue Y, Qu L, et al. Metal-free catalysts for oxygen reduction reaction. Chem Rev, 2015, 115: 4823-4892

2 Trogadas P, Coppens MO. Nature-inspired electrocatalysts and devices for energy conversion. Chem Soc Rev, 2020, 49: 3107-3141

3 Chen S, Qiu L, Cheng HM. Carbon-based fibers for advanced electrochemical energy storage devices. Chem Rev, 2020, 120: 2811-2878

4 Chong L, Wen J, Kubal J, et al. Ultralow-loading platinum-cobalt fuel cell catalysts derived from imidazolate frameworks. Science, 2018, 362: 1276-1281

5 Tan $\mathrm{P}$, Chen $\mathrm{B}, \mathrm{Xu} \mathrm{H}$, et al. Flexible $\mathrm{Zn}$ - and Li-air batteries: Recent advances, challenges, and future perspectives. Energy Environ Sci, 2017, 10: $2056-2080$

6 Huang L, Zheng CY, Shen B, et al. High-index-facet metal-alloy nanoparticles as fuel cell electrocatalysts. Adv Mater, 2020, 32: 2002849

7 Pandey J, Hua B, $\mathrm{Ng} \mathrm{W}$, et al. Developing hierarchically porous $\mathrm{MnO}_{x} /$ NC hybrid nanorods for oxygen reduction and evolution catalysis. Green Chem, 2017, 19: 2793-2797
8 Yan X, Jia Y, Yao X. Defects on carbons for electrocatalytic oxygen reduction. Chem Soc Rev, 2018, 47: 7628-7658

9 Li M, Zhao Z, Cheng T, et al. Ultrafine jagged platinum nanowires enable ultrahigh mass activity for the oxygen reduction reaction. Science, 2016, 354: 1414-1419

10 Zeng M, Liu Y, Zhao F, et al. Metallic cobalt nanoparticles encapsulated in nitrogen-enriched graphene shells: Its bifunctional electrocatalysis and application in zinc-air batteries. Adv Funct Mater, 2016, 26: 43974404

11 Wang MQ, Yang WH, Wang HH, et al. Pyrolyzed Fe-N-C composite as an efficient non-precious metal catalyst for oxygen reduction reaction in acidic medium. ACS Catal, 2014, 4: 3928-3936

12 Wang $\mathrm{K}$, Chen $\mathrm{H}$, Zhang X, et al. Iron oxide@graphitic carbon coreshell nanoparticles embedded in ordered mesoporous $\mathrm{N}$-doped carbon matrix as an efficient cathode catalyst for PEMFC. Appl Catal B-Environ, 2020, 264: 118468

13 Zhu C, Shi Q, Xu BZ, et al. Hierarchically porous $\mathrm{M}-\mathrm{N}-\mathrm{C}$ ( $\mathrm{M}=\mathrm{Co}$ and $\mathrm{Fe}$ ) single-atom electrocatalysts with robust $\mathrm{MN}_{x}$ active moieties enable enhanced ORR performance. Adv Energy Mater, 2018, 8: 1801956

14 Ghosh S, Barg S, Jeong SM, et al. Heteroatom-doped and oxygenfunctionalized nanocarbons for high-performance supercapacitors. Adv Energy Mater, 2020, 10: 2001239

15 Yang Y, Mao K, Gao S, et al. O-, N-atoms-coordinated Mn cofactors within a graphene framework as bioinspired oxygen reduction reaction electrocatalysts. Adv Mater, 2018, 30: 1801732

16 Sa YJ, Seo DJ, Woo J, et al. A general approach to preferential formation of active $\mathrm{Fe}-\mathrm{N}_{x}$ sites in $\mathrm{Fe}-\mathrm{N} / \mathrm{C}$ electrocatalysts for efficient oxygen reduction reaction. J Am Chem Soc, 2016, 138: 15046-15056

17 Xia D, Yang X, Xie L, et al. Direct growth of carbon nanotubes doped with single atomic $\mathrm{Fe}-\mathrm{N}_{4}$ active sites and neighboring graphitic nitrogen for efficient and stable oxygen reduction electrocatalysis. Adv Funct Mater, 2019, 29: 1906174

18 Liu J, Wan X, Liu S, et al. Hydrogen passivation of M-N-C $(\mathrm{M}=\mathrm{Fe}, \mathrm{Co})$ catalysts for storage stability and ORR activity improvements. Adv Mater, 2021, 33: 2103600

19 Lai Q, Zheng L, Liang Y, et al. Metal-organic-framework-derived Fe-N/ $\mathrm{C}$ electrocatalyst with five-coordinated $\mathrm{Fe}-\mathrm{N}_{x}$ sites for advanced oxygen reduction in acid media. ACS Catal, 2017, 7: 1655-1663

20 Tang J, Yamauchi Y. MOF morphologies in control. Nat Chem, 2016, 8: 638-639

21 Zhong L, Ding J, Qian J, et al. Unconventional inorganic precursors determine the growth of metal-organic frameworks. Coord Chem Rev, 2021, 434: 213804

22 Mohideen MIH, Pillai RS, Adil K, et al. A fine-tuned MOF for gas and vapor separation: A multipurpose adsorbent for acid gas removal, dehydration, and BTX sieving. Chem, 2017, 3: 822-833

23 Wu MX, Yang YW. Metal-organic framework (MOF)-based drug/cargo delivery and cancer therapy. Adv Mater, 2017, 29: 1606134

24 Zhu L, Liu XQ, Jiang HL, et al. Metal-organic frameworks for heterogeneous basic catalysis. Chem Rev, 2017, 117: 8129-8176

25 Bavykina A, Kolobov N, Khan IS, et al. Metal-organic frameworks in heterogeneous catalysis: Recent progress, new trends, and future perspectives. Chem Rev, 2020, 120: 8468-8535

26 Tang WQ, Zhao YJ, Xu M, et al. Controlling the stacking modes of metal-organic framework nanosheets through host-guest noncovalent interactions. Angew Chem Int Ed, 2021, 60: 6920-6925

27 Mileo PGM, Adil K, Davis L, et al. Achieving superprotonic conduction with a 2D fluorinated metal-organic framework. J Am Chem Soc, 2018, 140: $13156-13160$

28 Thorarinsdottir AE, Harris TD. Metal-organic framework magnets. Chem Rev, 2020, 120: 8716-8789

29 Ye Y, Cai F, Li H, et al. Surface functionalization of ZIF-8 with ammonium ferric citrate toward high exposure of Fe-N active sites for efficient oxygen and carbon dioxide electroreduction. Nano Energy, 2017, 38: 281-289

30 Zhang $\mathrm{H}$, Hwang $\mathrm{S}$, Wang $\mathrm{M}$, et al. Single atomic iron catalysts for oxygen reduction in acidic media: Particle size control and thermal activation. J Am Chem Soc, 2017, 139: 14143-14149

31 Wang $\mathrm{X}$, Dong A, Hu Y, et al. A review of recent work on using metal- 
organic frameworks to grow carbon nanotubes. Chem Commun, 2020, 56: $10809-10823$

32 Huang Q, Guo Y, Chen D, et al. Rational construction of ultrafine noble metals onto carbon nanoribbons with efficient oxygen reduction in practical alkaline fuel cell. Chem Eng J, 2021, 424: 130336

33 Fang G, Zhou J, Liang C, et al. MOFs nanosheets derived porous metal oxide-coated three-dimensional substrates for lithium-ion battery applications. Nano Energy, 2016, 26: 57-65

34 Qiao M, Wang Y, Wang Q, et al. Hierarchically ordered porous carbon with atomically dispersed $\mathrm{FeN}_{4}$ for ultraefficient oxygen reduction reaction in proton-exchange membrane fuel cells. Angew Chem Int Ed, 2020, 59: 2688-2694

35 Lv X, Li X, Yang C, et al. Large-size, porous, ultrathin NiCoP nanosheets for efficient electro/photocatalytic water splitting. Adv Funct Mater, 2020, 30: 1910830

36 Al-Ghouti MA, Da'ana DA. Guidelines for the use and interpretation of adsorption isotherm models: A review. J Hazard Mater, 2020, 393: 122383

37 Zhao H, Liu L, Vellacheri R, et al. Recent advances in designing and fabricating self-supported nanoelectrodes for supercapacitors. Adv Sci, 2017, 4: 1700188

38 Liu S, Wang F, Dong R, et al. Soft-template construction of 3D macroporous polypyrrole scaffolds. Small, 2017, 13: 1604099

39 Xie J, Zhang H, Li S, et al. Defect-rich $\mathrm{MoS}_{2}$ ultrathin nanosheets with additional active edge sites for enhanced electrocatalytic hydrogen evolution. Adv Mater, 2013, 25: 5807-5813

40 Jayakumar A, Antony RP, Wang R, et al. MOF-derived hollow cage $\mathrm{Ni}_{x} \mathrm{Co}_{3-x} \mathrm{O}_{4}$ and their synergy with graphene for outstanding supercapacitors. Small, 2017, 13: 1603102

41 Chai $\mathrm{L}, \mathrm{Hu} \mathrm{Z}$, Wang $\mathrm{X}$, et al. $\mathrm{Fe}_{7} \mathrm{C}_{3}$ nanoparticles with in situ grown CNT on nitrogen doped hollow carbon cube with greatly enhanced conductivity and ORR performance for alkaline fuel cell. Carbon, 2021, 174: 531-539

42 Wang $\mathrm{X}$, Chai L, Ding J, et al. Chemical and morphological transformation of MOF-derived bimetallic phosphide for efficient oxygen evolution. Nano Energy, 2019, 62: 745-753

43 Liu L, Zeng G, Chen J, et al. N-doped porous carbon nanosheets as $\mathrm{pH}$ universal ORR electrocatalyst in various fuel cell devices. Nano Energy, 2018, 49: 393-402

44 Liu W, Chu L, Zhang C, et al. Hemin-assisted synthesis of peroxidaselike Fe-N-C nanozymes for detection of ascorbic acid-generating bioenzymes. Chem Eng J, 2021, 415: 128876

45 Qiu B, Fan S, Wang Y, et al. Catalytic membrane micro-reactor with nano ZIF-8 immobilized in membrane pores for enhanced Knoevenagel reaction of benzaldehyde and ethyl cyanoacetate. Chem Eng J, 2020, 400: 125910

46 Li P, Wang H, Fan W, et al. Salt assisted fabrication of lignin-derived $\mathrm{Fe}, \mathrm{N}, \mathrm{P}, \mathrm{S}$ codoped porous carbon as trifunctional catalyst for $\mathrm{Zn}$-air batteries and water-splitting devices. Chem Eng J, 2021, 421: 129704

47 Liang $\mathrm{Y}, \mathrm{Li} \mathrm{Y}$, Wang $\mathrm{H}$, et al. $\mathrm{Co}_{3} \mathrm{O}_{4}$ nanocrystals on graphene as a synergistic catalyst for oxygen reduction reaction. Nat Mater, 2011, 10: 780-786

48 Zhou T, Zhang N, Wu C, et al. Surface/interface nanoengineering for rechargeable Zn-air batteries. Energy Environ Sci, 2020, 13: 1132-1153

49 Zhu D, Zhao Q, Fan G, et al. Photoinduced oxygen reduction reaction boosts the output voltage of a zinc-air battery. Angew Chem Int Ed, 2019, 58: 12460-12464

50 Du D, Zhao S, Zhu Z, et al. Photo-excited oxygen reduction and oxygen evolution reactions enable a high-performance $\mathrm{Zn}$-air battery. Angew Chem Int Ed, 2020, 59: 18140-18144

51 Lyu Z, Zhang XG, Wang Y, et al. Amplified interfacial effect in an atomically dispersed $\mathrm{RuO}_{x}$-on-Pd $2 \mathrm{D}$ inverse nanocatalyst for highperformance oxygen reduction. Angew Chem Int Ed, 2021, 60: 1609316100

Acknowledgements This work was financially supported by the Basic Science and Technology Research Project of Wenzhou, Zhejiang Province (G20190007 and ZG2017027), the BUCT-WZU Joint Fund (KH2012031), and the State Key Laboratory of Structural Chemistry, Chinese Academy of Sciences (20190008).

Author contributions Qian J conceived the idea and supervised the project. Zhu K and Ji X contributed to the experiments. Chen D conducted the DFT calculations. The paper was primarily written by Qian J and Sun Q. All authors contributed to the general discussion.

Conflict of interest The authors declare that they have no conflict of interest.

Supplementary information Supporting data are available in the online version of the paper.

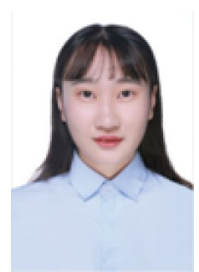

Qiuhong Sun received her bachelor's degree from Wenzhou University in 2020, and now she is a graduate student at Wenzhou University. Her current research focuses on the design and synthesis of MOF-derived hierarchically porous materials using silica templates for electrochemical applications.

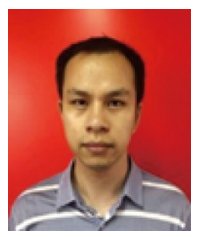

Jinjie Qian is an associate professor at the College of Chemistry and Materials Engineering, Wenzhou University. He received his $\mathrm{PhD}$ degree from Fujian Institute of Research on the Structure of Matter, Chinese Academy of Sciences (CAS), under the supervision of CAS Academician Maochun Hong. His current research focuses on the electrochemical research on carbon nanomaterials from metal-organic frameworks for energy storage and conversion.

\section{金属有机框架衍生的三维有序多孔碳纳米材料用于 高效碱性锌空气电池}

孙秋红 ${ }^{1}$, 朱楷 ${ }^{1}$, 季湘丽 $^{1}$, 陈丹丹 ${ }^{1}$, 韩承 $^{1}$, 黎挺挺 ${ }^{2}$, 胡悦 $^{1}$, 黄少铭 ${ }^{3}$, 钱金杰 ${ }^{1,2 *}$

摘要 设计和制备高催化活性和高稳定性的非贵金属催化剂对金属-空 气电池和燃料电池研究具有重要意义. 本文中, 我们通过二氧化硅模板 法和碳纳米管 $(\mathrm{CNT})$ 生长对金属有机框架ZIF-8进行碳化，合成了一种 分级三维有序多孔碳纳米材料. 进一步通过添加铁源, 高温热解获得的 多孔mFenC-CNT具有精细的 $\mathrm{Fe}$ 基纳米颗粒以及原子分散 $\mathrm{Fe}-\mathrm{N}_{x}$ 位点. 三维多孔结构降低了电荷传输阻力, 使得铁、氮共掺杂碳表现出与商 业 $\mathrm{Pt} / \mathrm{C}$ 相当的氧还原反应(ORR)性能. 同时, 在尿素催化下得到的交织 CNT在电化学过程中进一步缩短了离子和电子的扩散途径. 实验和理 论计算结果表明, 优化后的 $\mathrm{mFeNC}$-CNT在锌空气电池上表现出较高的 ORR活性. 综上, 这项工作为用于能量存储、转换和传输应用的高性能 非贵金属基电催化剂的合理设计和简便合成提供了一种有前景的 策略. 